\title{
Structural insight into enhanced calcium indicator GCaMP3 and GCaMPJ to promote further improvement
}

\author{
Yingxiao Chen*, Xianqiang Song*, Sheng Ye, Lin Miao, Yun Zhu, Rong-Guang Zhang ${ }^{\bowtie}$,Guangju Ji $^{\bowtie}$ \\ National Laboratory of Biomacromolecules, Institute of Biophysics, Chinese Academy of Sciences, Beijing 100101, China \\ $\triangle$ Correspondence: gj28@ibp.ac.cn (G. Ji), rzhang@sun5.ibp.ac.cn (R.-G. Zhang) \\ Received October 8, 2012 Accepted November 28, 2012
}

\begin{abstract}
Genetically encoded $\mathrm{Ca}^{2+}$ indicators (GECl) are important for the measurement of $\mathrm{Ca}^{2+}$ in vivo. GCaMP2, a widelyused $\mathrm{GECl}$, has recently been iteratively improved. Among the improved variants, GCaMP3 exhibits significantly better fluorescent intensity. In this study, we developed a new GECI called GCaMPJ and determined the crystal structures of GCaMP3 and GCaMPJ. GCaMPJ has a 1.5fold increase in fluorescence and 1.3-fold increase in calcium affinity over GCaMP3. Upon $\mathrm{Ca}^{2+}$ binding, GCaMP3 exhibits both monomeric and dimeric forms. The structural superposition of these two forms reveals the role of Arg-376 in improving monomer performance. However, GCaMPJ seldom forms dimers under conditions similar to GCaMP3. Structural and mutagenesis studies on Tyr-380 confirmed its importance in blocking the cPEGFP $\beta$-barrel holes. Our study proposes an efficient tool for mapping $\mathrm{Ca}^{2+}$ signals in intact organs to facilitate the further improvement of GCaMP sensors.
\end{abstract}

KEYWORDS genetically encoded calcium indicator, mutants, crystal structure, fluorescentintensity, dimerization

\section{INTRODUCTION}

Genetically encoded $\mathrm{Ca}^{2+}$ indicators (GECl) are important for the physiological measurement of $\mathrm{Ca}^{2+}$ dynamics in tissues and organs (Kotlikoff, 2007; Hires et al., 2008). Green fluorescent protein (GFP) has been widely used as a major component for GECI. Intact GFP presents a cage-like structure with $11 \beta$-sheets that form a barrel. Three consecutive residues (Ser65-Tyr66-Gly67) are post translational cyclized to form the fluorophore, which is attached to the $\alpha$-helix buried almost

*These authors contributed equally to the work.

(c) Higher Education Press and Springer-Verlag Berlin Heidelberg 2013 perfectly in the center of $\beta$-barrel (Ormo et al., 1996; Yang et al., 1996; Brejc et al., 1997). The protonated and deprotonated fluorophore in wild-type GFP respectively generate the major excitation peak at a wavelength of $395 \mathrm{~nm}$ and a minor peak at $475 \mathrm{~nm}$. By contrast, enhanced GFP (EGFP; GFP-S65T mutant) has a unitary deprotonated fluorophore and a single excitation peak at $489 \mathrm{~nm}$. Moreover, EGFP can yield an enhanced green fluorescence (Ormo et al., 1996).

A GCaMP sensor is a widely-used typical GECI that was first constructed based on a central circularly permutated EGFP (cpEGFP), with calmodulin (CaM) and its target peptide of myosin light chain (M13 peptide) at its $\mathrm{C}$ and $\mathrm{N}$ terminals, respectively (Nagai et al., 2001). However, GCaMP1.0 (GCaMP version 1.0) and the subsequently improved GCaMP1.6 exhibited fluorescence degradation at a tissue temperature of $37^{\circ} \mathrm{C}$ (Ohkura et al., 2005), thus limiting their imaging applications. GCaMP2 was then discovered, displaying good thermal stability, a fourfold increase in dynamic range, and reduced $\mathrm{pH}$ sensitivity. These advantages can mainly be attributed to artificial poly-His linker (RSET) coincidentally added in the $\mathrm{N}$ terminal of GCaMP2, which enabled the sensor to be fully functional at $37^{\circ} \mathrm{C}$ (Tallini et al., 2006). Despite having been used in characterizing $\mathrm{Ca}^{2+}$ signaling in the heart, smooth muscle, cortical brain slice of mice (Ji et al., 2004; Tallini et al., 2006; Hires et al., 2008), the low baseline fluorescence and poor signal-tonoise ratio hinders GCaMP2 from accurately detecting the most rapid physiological $\mathrm{Ca}^{2+}$ signals, especially in intact organs.

The crystal structure of GCaMP2 was examined to facilitate further understanding and rational improvement of its working mechanism (Wang et al., 2008; Akerboom et al., 2009). The overall structure of cpEGFP in GCaMP2 is almost identical to the structure of cpEGFP. Upon $\mathrm{Ca}^{2+}$ binding, the calcium-coordinated M13/CaM complex significantly interacts with cpEGFP, 
thus affecting the hydrogen bond environments around the fluorophore and consequently changing the spectral properties of the whole sensor protein. Meanwhile, the crystal structure of a relatively dim dimeric form of $\mathrm{Ca}^{2+}$ bound GCaMP2 was reported in other studies (Wang et al., 2008; Akerboom et al., 2009).

Based on structural information and semi-rational library screening, a significantly improved version called GCaMP3 was subsequently created. GCaMP3 was created with one deletion and three substitutions: Arg-2 was removed, whereas Met-66, Thr-116, and Asn-363 were respectively replaced by Lys-65, Val-115, and Asp-362 (Tian et al., 2009). Compared with GCaMP2, GCaMP3 exhibits 3.9-fold in vivo baseline fluorescence, three fold dynamic range, and 1.3-fold calcium affinity. GCaMP3 has been successful in detecting $\mathrm{Ca}^{2+}$ signal neurons (Dombeck et al., 2010; Seelig et al., 2010; Borghuis et al., 2011) and is considered as a recent breakthrough in human embryonic stem cell-based heart transplantation studies (Shiba et al., 2012).

Meanwhile, the improvement of GCaMP sensor and other GECls for wider and more accurate use in calcium signaling measurement in vivo is ongoing (Zhao et al., 2011). Based on extensive studies and optimization trials, achieving further improvement in the performance of GCaMP sensors, given the complicated fluorescence properties of GFP (Brejc et al., 1997; Tsien, 1998), as well as realizing dynamic allostery at the interface between the M13/CaM complex and fluorophore center (Wang et al., 2008; Akerboom et al., 2009) and facilitating its innate tendency to form a calcium insensitive dimer (Wang et al., 2008), remains challenging.

Although previous studies have improved $\mathrm{Ca}^{2+}$ signal property measurement and provided plausible explanations for the enhancement of GCaMP2, the study of $\mathrm{Ca}^{2+}$ kinetics in intact organs, especially in terms of the exact function of substituted residues, remains unclear. In the present study, we developed a new generation of GECl called GCaMPJ and thoroughly investigated GCaMPJ and GCaMP3 through both spectroscopic and structural means to provide adequate evidence explaining the calcium-stimulated fluorescence mechanism of the enhanced GCaMP3 sensor.

\section{RESULTS AND DISCUSSION}

GCaMP3 $\cdot \mathrm{Ca}^{2+}$ in monomeric form exhibits better spectroscopic performance than in dimeric form

Our SEC analysis showed that in the absence of $\mathrm{Ca}^{2+}$, GCaMP3 was expressed in monomeric form. The oligomeric distribution of GCaMP3 evidently changed in a $\mathrm{Ca}^{2+}$-saturated environment. Through SEC, GCaMP3 $\cdot \mathrm{Ca}^{2+}$ was separated into two fractions: a small population of dimeric form (30\%) and a large population of monomeric form (Fig. 1C). The MALS assay confirmed the existence of the dimeric and monomeric forms of GCaMP3 (102.6 kDa vs. $55.1 \mathrm{kDa}$ ). The SEC-isolated dimeric fraction of GCaMP3 $\cdot \mathrm{Ca}^{2+}$ can hardly disassemble into monomeric form again, based on SEC analysis three days later. Similarly, the SEC-isolated monomeric fraction of GCaMP3. $\mathrm{Ca}^{2+}$ in solution has not form dimers after a week even longer. Nevertheless, the monomeric GCaMP3 $\cdot \mathrm{Ca}^{2+}$ used for crystallization finally crystallized in dimeric form, as confirmed by the solved structures. According to previous studies, the dimerization tendency at high protein concentration and crystallization was also observed in GCaMP2 (Wang et al., 2008; Akerboom et al., 2009).

The spectroscopic properties of $\mathrm{GCaMP} 3 \cdot \mathrm{Ca}^{2+}$ were also characterized in monomeric and dimeric forms. In a $\mathrm{pH} 7.5$ solution close to intracellular conditions, dimeric GCaMP3 $\cdot \mathrm{Ca}^{2+}$ exhibited a twofold decrease in fluorescence intensity compared with the monomeric form (Fig. 1B). Both dimeric and monomeric GCaMP3 $\mathrm{Ca}^{2+}$ were absorbed maximally at $\sim 500 \mathrm{~nm}$, but with remarkably different ratios of A500/ A400. Dimeric GCaMP3 $\mathrm{Ca}^{2+}$ exhibited a fourfold decrease in A500/A400 compared with the monomeric form (Fig. 1B). Apparently, monomeric GCaMP3. $\mathrm{Ca}^{2+}$ exhibits better spectroscopic performance than the dimeric form.

As a GECl, GCaMPs are primarily used to study $\mathrm{Ca}^{2+}$ fluxes in vivo. Upon $\mathrm{Ca}^{2+}$ binding, GCaMP can exhibit two different oligomeric forms with distinguished spectroscopic properties (Wang et al., 2008; Akerboom et al., 2009). However, the intracellular dimer/monomer ratio is difficult to investigate, thus in vivo, this could lead to an inaccurate quantitative interpretations of the imaging results. Spectroscopic studies on GCaMPs were previously conducted using dimer/monomer mixtures or N-terminal truncation lacking RSET, which can maintain the monomeric state even upon $\mathrm{Ca}^{2+}$ binding (Wang et al., 2008; Akerboom et al., 2009). Herein, SEC-isolated monomeric and dimeric GCaMP3 $\mathrm{Ca}^{2+}$ were employed for analysis and provided accurate spectroscopic properties. in vivo, the notable difference between these two forms provides a potential method to calculating the dimer/monomer ratio of GCaMPs in vivo simply based on the spectroscopic data.

\section{Overall structure of dimeric GCaMP3 $\cdot \mathrm{Ca}^{2+}$ exhibits} identical architecture with dimeric GCaMP2 $\cdot \mathrm{Ca}^{2+}$

According to the previous extensive structural studies on GCaMP2 (Wang et al., 2008; Akerboom et al., 2009), $\mathrm{Ca}^{2+}$ binding triggers dramatic conformational rearrangement of the M13 peptide and CaM. To achieve the crystal structure of GCaMP3, we crystallized both monomeric and dimeric forms of GCaMP3 $\mathrm{Ca}^{2+}$ under different conditions and solved five structures of GCaMP3 $\cdot \mathrm{Ca}^{2+}$. In these structures, calciumcoordinated GCaMP3 forms a properly folded dimer in domain-swapped mode (Fig.1D), which similar to the dimeric GCaMP2 $\cdot \mathrm{Ca}^{2+}$ structures (Wang et al., 2008; Akerboom et al., 2009). In one GCaMP3 $\cdot \mathrm{Ca}^{2+}$ dimer, the M13 peptide of each protomer forms a helix and drills into the CaM of the opposite protomer, generating two tightly tethered $\mathrm{M} 13 / \mathrm{CaM}$ complexes. The abundant interactions between M13 helix and CaM facilitate an extremely stable dimeric state of GCaMP3. $\mathrm{Ca}^{2+}$, consistent with the fact that the SEC-isolated dimeric fraction 
A

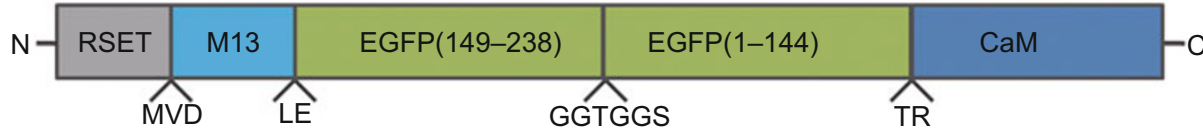

B

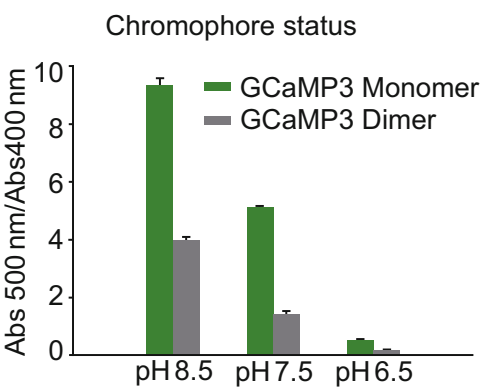

Fluorescence Intensity

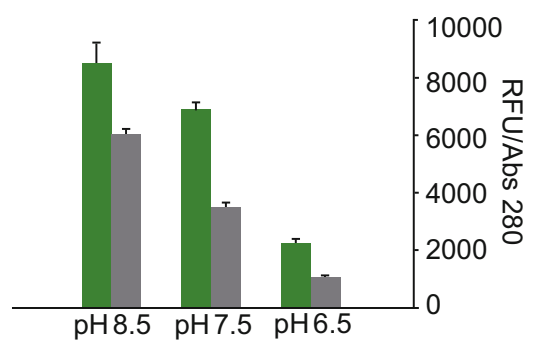

C

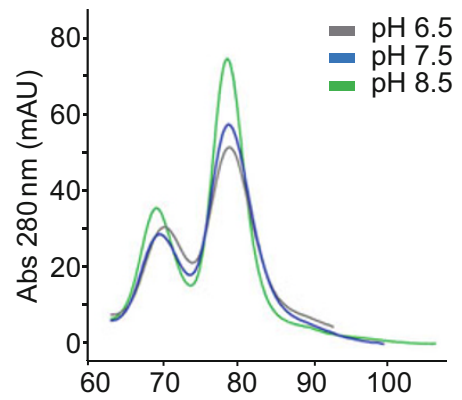

D

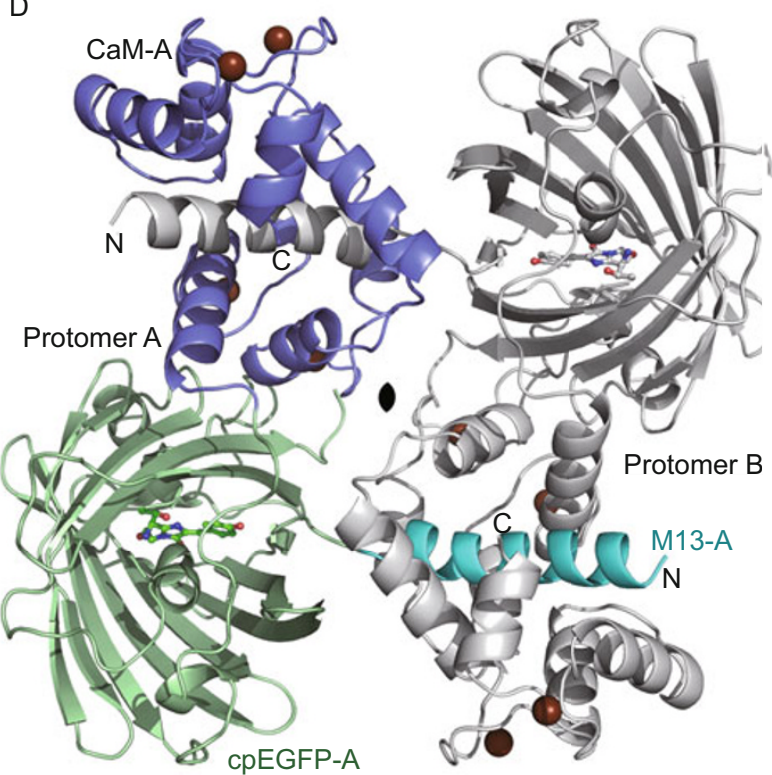

E
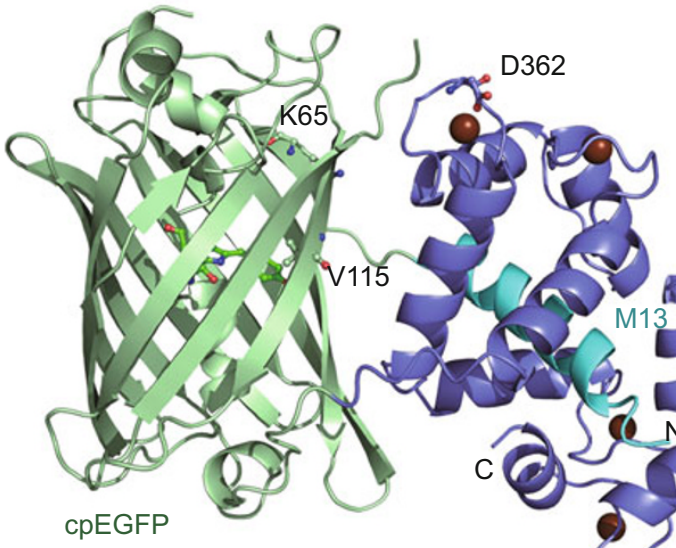

$\mathrm{CaM}$

Figure 1. Properties and structure of GCaMP3. (A) Schematic presentation of the GCaMP3 fusion protein showing the domain organization. (B) Absorbance ratio of 500-400 nm and normalized fluorescence of dimeric GCaMP3 (gray) and monomeric GCaMP3 (green). This ratio shows fluorophore status. The fluorescence is normalized to Abs $280 \mathrm{~nm}$ of each part. (C) SEC of calcium bound GCaMP3 in different $\mathrm{pH}$ buffers after affinity purification. (D) Cartoon representation of dimeric GCaMP3. $\mathrm{Ca}^{2+}$ with a twofold rotation symmetry. One protomer is colored light gray, and the other is colored based on domain (M13 in cyan, cpEGFP in light green, and CaM in purple). Fluorophores of two protomers are depicted in ball-and-sticks, and calcium ions in brown spheres. (E) Cartoon representation of monomeric GCaMP3 ${ }_{\triangle R S E T} \cdot \mathrm{Ca}^{2+}$, colored as in (D). Aside from its fluorophore and coordinated calcium, the three substitution residues Lys-65, Val-115, and Asp-362 are also highlighted in ball-and-stick.

of GCaMP3 $\cdot \mathrm{Ca}^{2+}$ is maintained as dimer in a solution for three days even longer. Interestingly, the SEC-isolated monomeric GCaMP $3 \cdot \mathrm{Ca}^{2+}$ eventually crystallized as dimers, probably because of the high protein concentration under crystallization conditions.

Two parts of dimeric GCaMP3 $\cdot \mathrm{Ca}^{2+}$ were not traced because of their poor electron densities. One part was the RSET module (residues 1-35) at the N-terminus, which was demonstrated to be critical for the dimerization of GCaMPs. A
RSET-truncated GCaMP mutant maintains monomeric state both in solution and in crystal structures. Thus, the question emerges as to how RSET initiates or promotes the assembly of GCaMP dimers. Considering the absence of RSET in our GCaMP $3 \cdot \mathrm{Ca}^{2+}$ structures, the answer to this question remains unclear. The other missing part in the GCaMP3 $\cdot \mathrm{Ca}^{2+}$ structures is the artificial loop connecting the circularly permuted $\mathrm{N}$ and C-terminals of EGFP. Similar to our structure, in previously reported or unreported GCaMP structures, the RSET and the 


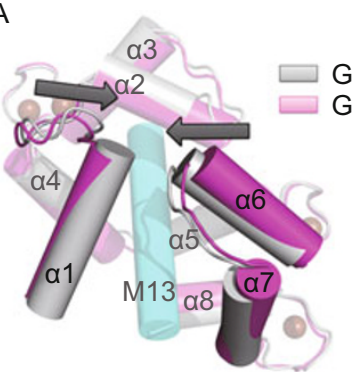

B

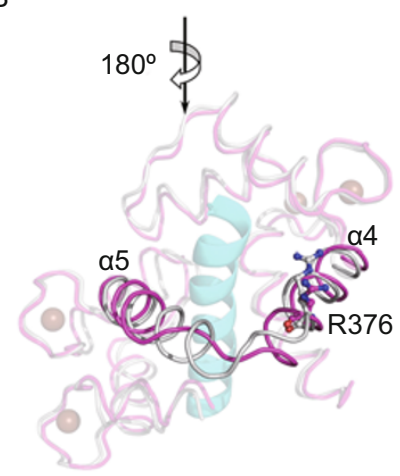

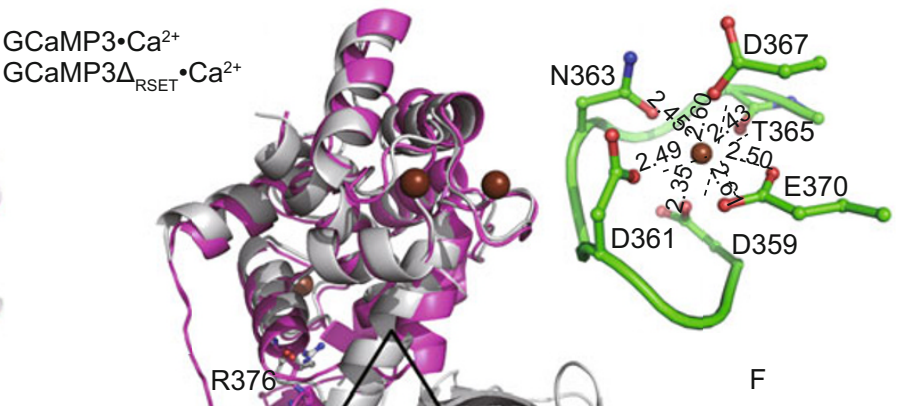
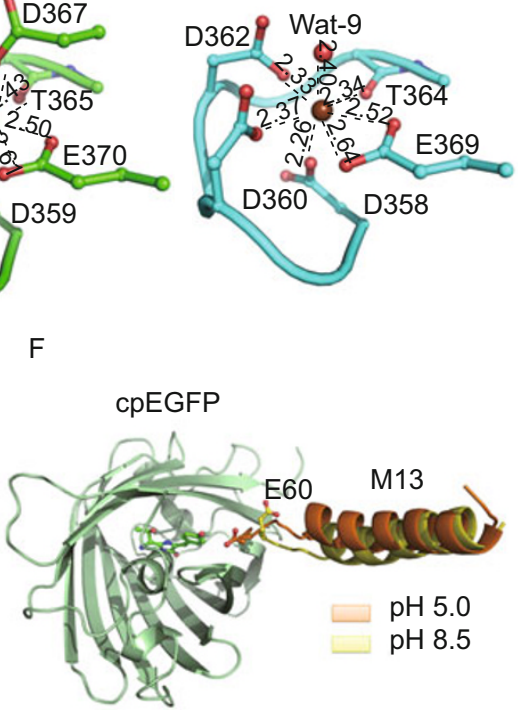

Figure 2. Structural analysis of GCaMP3. (A) Superposition of the CaMs in dimeric GCaMP3. $\mathrm{Ca}^{2+}$ (light gray) and monomeric $\mathrm{GCaMP}_{\triangle R S E T} \cdot \mathrm{Ca}^{2+}$ (magenta). M13 peptide is colored cyan. All helices are shown in cylinders and properly labeled. Regions with obvious difference are highlighted and indicated by gray arrows. (B) Superposition of the CaMs shown from the opposite direction of (A). All helices are shown in ribbons except for M13 peptide. Helices a4, a5, and the loop between them are highlighted. Residue Arg-376 is shown in ball-and-stick representation. (C) Superposition of GCaMP ${ }_{\triangle R S E T} \cdot \mathrm{Ca}^{2+}$ (magenta) and GCaMP3 $\cdot \mathrm{Ca}^{2+}$ (light gray, CaM is removed and replaced by the CaM of its symmetric protomer). The rotation of cpEGFP is indicated as approximately $60^{\circ}$. Two fluorophores and Arg-376 are highlighted in ball-and-stick. (D) The calcium binding site with Asn-363 in monomeric GCaMP2 ${ }_{\triangle R S E T} \cdot \mathrm{Ca}^{2+}(\mathrm{PDB}$ entry: 3EVR). Residues involved in coordination are represented in ball-and-stick. Calcium ion is shown in brown sphere. Coordination bonds are indicated with black dash lines with length labeled properly. (E) The calcium binding site with Asp-362 in GCaMP3 ${ }_{\triangle R S E T}{ }^{\circ} \mathrm{Ca}^{2+}$ represented and colored as in (D). (F) Superposition of the M13 peptides of GCaMP3 $\cdot \mathrm{Ca}^{2+}$ at different $\mathrm{pH}$ conditions $(\mathrm{pH} 5.0$ in orange and pH 8.5 in yellow). Fluorophore and residue Glu-60 are highlighted in ball-and-stick representation.

artificial loop are seldom observed.

Monomeric GCaMP3 ${ }_{\triangle \mathrm{RSEE}} \cdot \mathrm{Ca}^{2+}$ represents the structure of
monomeric GCaMP3 $\mathrm{Ca}^{2+}$ To investigate the structure of monomeric GCaMP3. $\mathrm{Ca}^{2+}$, a truncation mutant lacking the $\mathrm{N}$-terminal RSET module $\left(G C a M P 3_{\triangle R S E T}\right)$ was used for crystallization. The crystal structure of $\mathrm{GCaMP} 3_{\triangle \mathrm{RSET}} \cdot \mathrm{Ca}^{2+}$ presents a monomeric form distinguished from dimeric GCaMP3. $\mathrm{Ca}^{2+}$ (Fig. 1E). Without domain swap, the M13 peptide penetrates into the CaM of the same molecule, forming a M13/CaM complex similar to that in dimeric GCaMP3 $\mathrm{Ca}^{2+}$ (root-mean-square deviation of $1.8 \AA$ for $142 \mathrm{Ca}$ of CaM).

However, the overall architecture of both dimeric and monomeric GCaMP3. $\mathrm{Ca}^{2+}$ is nearly identical to the corresponding form of GCaMP2 $\mathrm{Ca}^{2+}$ because mutations from GCaMP2 to GCaMP3 are minor. Aside from the fact that Arg-2 deletion prevents degradation, Lys-65, Val-115, and Asp-362 of GCaMP3 are the only three substitution residues. Both Lys-65 and Val-
115 are located on the $\beta$-barrel of cpEGFP, whereas Asp-362 is located at an EF hand motif of CaM (Fig. 1E). None of these three residues are in a conformationally flexible region. Apparently, although GCaMP3 exhibits an almost three fold increase in fluorescence dynamic range, our structures reveal that this increase was not gained through significant conformational changes.

Further super imposition unveiled a slight contraction of the CaM in dimeric GCaMP3. $\mathrm{Ca}^{2+}$, which holds the $\mathrm{M} 13$ peptide tighter than the CaM in monomeric GCaMP3 ${ }_{\triangle \mathrm{RSET}} \mathrm{Ca}^{2+}$ (Fig. 2A). CaM grasps M13 in a manner similar to a palm holding a rod, where the major interactions between two opposite parts of CaM occur at the C-terminus of helix $\alpha 2$ and of helix $\alpha 6$. On the other hand, in dimeric GCaMP3. $\mathrm{Ca}^{2+}$, loop $\alpha 6-\alpha 7$ and loop a1- $\alpha 2$ move toward each other (distance decrease $>2 \AA$, as shown with arrows in Fig. $2 A$ ), thus introducing new hydrogen bond interactions between these two loops. Given that the different structures of the dimeric GCaMP3. $\mathrm{Ca}^{2+}$ that we solved show similar contractions, excluding the explanation that the 
more compact M13/CaM complex may be attributed to crystal packing is reasonable.

\section{Monomeric GCaMP ${ }_{\triangle R S E T} \cdot \mathrm{Ca}^{2+}$ further limited the solvent accessibility to the $\beta$-barrel hole}

A significant conformational difference between monomeric GCaMP3 ${ }_{\triangle R S E T} \cdot \mathrm{Ca}^{2+}$ and dimeric GCaMP3 $\cdot \mathrm{Ca}^{2+}$ was observed in the region from helix $a 4$ to $a 5$. The helix $a 4$ of monomeric $\mathrm{GCaMP}_{\triangle \mathrm{BRET}} \cdot \mathrm{Ca}^{2+}$ is one turn longer at the C-terminus than that in dimeric GCaMP3 $\cdot \mathrm{Ca}^{2+}$. By contrast, the helix a5 is one turn shorter at the $\mathrm{N}$-terminus in $\mathrm{GCaMP} 3_{\triangle \mathrm{RSET}} \cdot \mathrm{Ca}^{2+}$ than in GCaMP3 $\cdot \mathrm{Ca}^{2+}$. As a result, loop a4-a5 undergoes remarkable conformational change between these two oligomeric states (Fig. 2B). This allostery could be a consequence of distinguished orientations of the cpEGFP to $\mathrm{CaM}\left(\sim 60^{\circ}\right.$ rotation, Fig. 2C).

A hole introduced by circular permutation exists in the $\beta$-barrel of cpEGFP. In monomeric GCaMP3 ${ }_{\triangle R S E T} \cdot \mathrm{Ca}^{2+}$, this hole is blocked by the last turn of the C-terminal of helix a4, whereas in dimeric GCaMP3 $\cdot \mathrm{Ca}^{2+}$, the hole faces the N-terminal of helix $\alpha 5$ and is fairly open to the solvent. Solvent accessibility to this hole is believed to be a key factor in GCaMPs' fluorescence performance. $\mathrm{Ca}^{2+}$-coordinated $\mathrm{CaM}$ is believed to block the hole to rescue the fluorescence activity of cpEGFP. Monomeric GCaMP sout performed dimeric ones in terms of limitation solvent access to the hole. Apparently, GCaMP3 fits the same theory.

Notably, Arg-376 may be an important factor in facilitating the stabilization of anionic fluorophore in monomeric GCaMP3 ${ }_{\triangle R S E T} \cdot \mathrm{Ca}^{2+}$. According to structural comparison, Arg376 is the $\mathrm{N}$-terminal point from where helix $\alpha 4$ adopts a different conformation (Fig. 2B and 2C). In dimeric GCaMP3. $\mathrm{Ca}^{2+}$, Arg-376 faces the hollow channel between two protomers and is thus incapable of participating in fluorophore interactions. By contrast, the side chain of Arg-376 in GCaMP3 ${ }_{\triangle R S E T} \cdot \mathrm{Ca}^{2+}$ extrudes toward the phenol group of fluorophore and forms a hydrogen bond bridge with it via a water molecule. The hydrogen bond between water and the fluorophore hydroxyl group is one of the two hydrogen bonds holding the deprotonated phenolate. The $\mathrm{NH} 2$ of Arg-376 side chain thus acts as the $\mathrm{H}^{+}$ receptor to stabilize the fluorophore at a deprotonated status. Lacking this restriction, GCaMP3. $\mathrm{Ca}^{2+}$ in dimeric form has a poorly stabilized anionic fluorophore and relative dim fluorescence intensity.

\section{Lys-65 and Val-115 are essential to GCaMP3's enhanced fluorescence activity}

The contribution of M66K (Lys-65 in GCaMP3) increased the dynamic range and baseline fluorescence of GCaMPs in cell assay (Tian et al., 2009). The side chains of both Met66 of GCaMP2 and Lys65 of GCaMP3 branched out of the protein surface, but the chains did not exhibit an evident of interaction with the surrounding residues. Lys-65 is located at the first $\beta$-strand of cpEGFP, only five residues away from the artificial linker connecting M13 peptide and cpEGFP. A possible explanation could be that Lys-65 affects the flexibility of the linker between M13 and cpEGFP and consequently influences the M13/CaM complex. Nevertheless, more solid evidence is still needed.

Among the three substituted residues of GCaMP3, (T116V Val-115 in GCaMP3) is the only one around the fluorophore. To reveal the exact function of Val-115, we mutated it back to Thr $\left(\right.$ GCaMP3 $\left._{V_{115 T}}\right)$. Compared with wild-type GCaMP3, the mutant exhibits a twofold decrease in fluorescence intensity with similar baseline fluorescence (Fig. 3D and 3E). Moreover, GCaMP $3_{\text {V115T }}$ exhibits a blue-shifted excitation spectrum compared with GCaMP3, which is close to that of GCaMP2 (Fig. 3C). The calcium affinity of GCaMP3 ${ }_{\mathrm{V} 115 \mathrm{~T}}$ is approximately $12 \%$ lower than that of the wild-type $(261 \pm 11 \mathrm{nmol} / \mathrm{L}$ vs. $230 \pm 3 \mathrm{nmol} / \mathrm{L}, P<0.01$ paired $t$-test, Fig. 3D). All these data prove that Val-115 could be the most essential among the three substitution residues, thus facilitating the comprehensive enhancement of fluorescence activity.

This essential Val-115 was also investigated structurally. Being a hydrophobic residue, the side chain of Val-115 does not form a hydrogen bond with nearby atoms (Fig. 3A). Hence, the hydroxyl group of fluorophore, is tethered by only two hydrogen bonds with water molecules, lacking the important hydrogen bond with Thr-116 in GCaMP2 (Fig. 3A). In the structural studies of GCaMP2 by Wang et al., Thr-116 was believed to contribute to the stabilization of the anionic phenolate by forming a hydrogen bond. Loss of its interaction with phenolic oxygen caused by rotation of the Thr-116 side chain in both structures of cpEGFP and GCaMP2 dimer were believed to result in the neutral low-fluorescent state (Wang et al., 2008). However, the absorbance spectra in our study revealed two phenomena (Fig. 3B). First, valine substitution, which is supposed to destabilize the deprotonated chromophore, did not significantly affect the fluorophore deprotonation in a neutral and alkaline environment. This phenomenon could be explained by the stabilization of the water molecule by Arg-376 reacting from CaM, which donates a hydrogen bond to the phenolic oxygen of the chromophore (Fig. 3A). Second, with or without calcium, GCaMP3 exhibits significant absorption at the high energy band with even more absorption at the low energy band compared with GCaMP $3_{V_{115}}$. However, the exact mechanism remains unclear.

In GFP, the corresponding mutation site T203V has been thoroughly studied and was believed to increase the excitedstate proton transfer (ESPT) of GFP (Kummer et al., 2000; Jung et al., 2005; Akerboom et al., 2009). Comparing the two hydrogen bond networks around fluorophore, the distance between Ser-117 and the water molecule which was bonded by hydrogen to fluorophore in GCaMP3 became significantly smaller ( $3.12 \AA$ vs. $3.99 \AA$ ). This hydrogen bond evidently facilitates the ESPT pathway in GCaMP3 with Glu-135 as the final acceptor (Stoner-Ma et al., 2005). However, ESPT accounts for the green light emission from the excitation of the neutral phenol group in ground-state equilibrium corresponding to low 
A

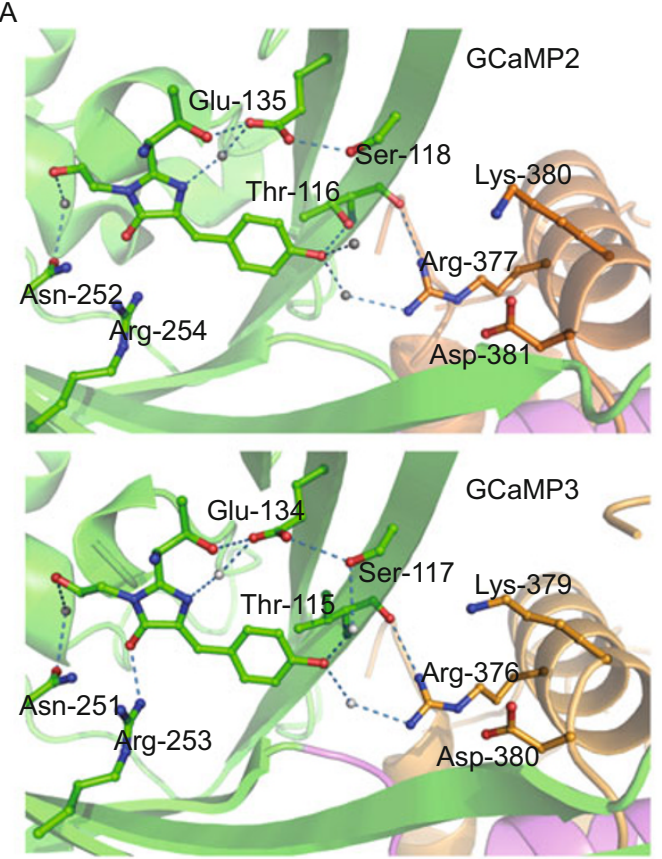

$\mathrm{B}$

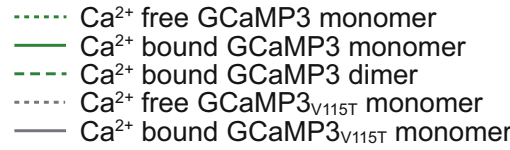

-..... $\mathrm{Ca}^{2+}$ free GCaMP3 monomer

-... $\mathrm{Ca}^{2+}$ bound GCaMP3 dimer

$\mathrm{Ca}^{2+}$ bound GCaMP3 3 $115 \mathrm{~T}$ monomer
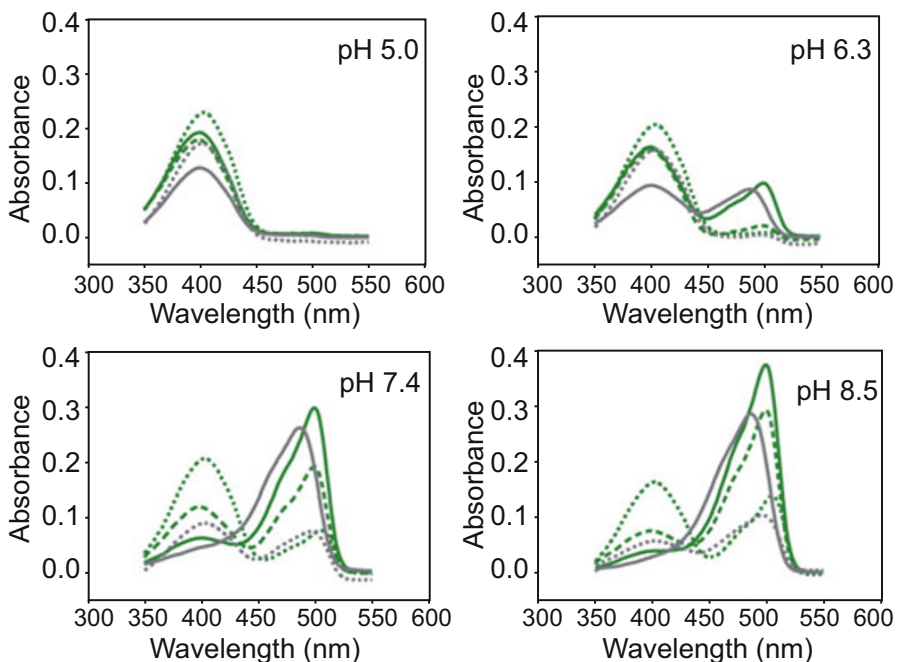

C

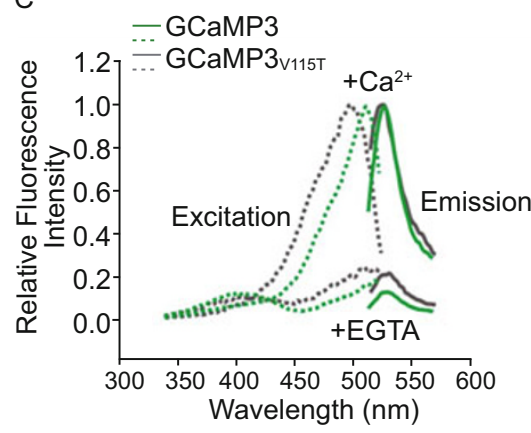

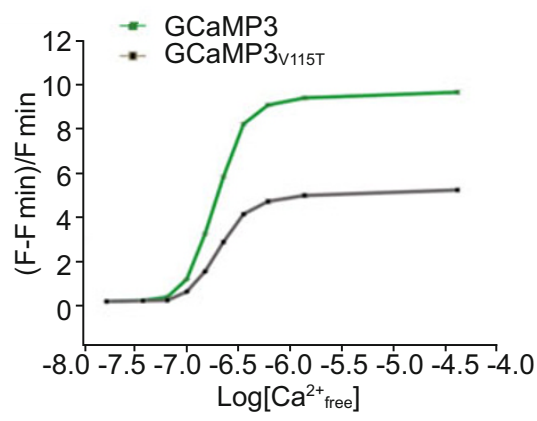

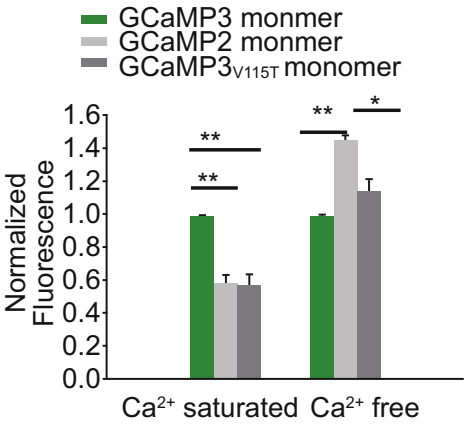

Figure 3. Function of Val-115 in GCaMP3. (A) Close-up view of the fluorophore-interacting residues in $\mathrm{Ca}^{2+}$-bound monomeric GCaMP2(top, PDB code 3EVR) and $\mathrm{Ca}^{2+}$-bound monomeric GCaMP3 (bottom). Hydrogen bonds are shown as dashed lines. (B) Absorbance spectra of monomeric GCaMP3 (green) and GCaMP3 ${ }_{\mathrm{V} 115 \mathrm{~T}}$ (gray) are measured without $\mathrm{Ca}^{2+}$ (10 mmol/L EGTA; short dash line) or with $\mathrm{Ca}^{2+}\left(1 \mathrm{mmol} / \mathrm{L}\right.$; solid line), and the $\mathrm{Ca}^{2+}$ bound dimeric GCaMP3 (long dashed line) at different pH values. (C) Fluorescence spectra of GCaMP3 (green) and GCaMP3 ${ }_{\mathrm{V} 115 \mathrm{~T}}$ (gray) with $1 \mathrm{mmol} / \mathrm{L} \mathrm{Ca}{ }^{2+}$ or $10 \mathrm{mmol} / \mathrm{L}$ EGTA in MOPS buffer. The fluorescence intensity of each indicator is normalized to the peak of the calcium-saturated spectrum. (D) $\mathrm{Ca}^{2+}$ titration assay shows dynamic range of GCaMP3 (green) and GCaMP3 ${ }_{\mathrm{V} 115 \mathrm{~T}}$ (gray) in MOPS buffer. (E) Normalized fluorescence intensity of $\mathrm{Ca}^{2+}$ saturated state $\left(1 \mathrm{mmol}^{2} \mathrm{~L} \mathrm{Ca}^{2+}\right)$ and Ca ${ }^{2+}$ free state (10 mmol/L EGTA) of GCaMP3 monomer (green), GCaMP2 monomer (light gray) and GCaMP3 ${ }_{\mathrm{V} 115 \mathrm{~T}}$ monomer (gray) in MOPS buffer. Fluorescence intensity was normalized to the brightness of GCaMP3 in both states.

energy band, whereas fluorescence emission from the excited anionic phenolate group in ground-state equilibrium does not involve proton motion (Chattoraj et al., 1996; Stoner-Ma et al., 2005). In calcium imaging experiments, GCaMPs are used at the maximum excitation of the indicator, which aims at the deprotonated part. Thus, the ESPT theory cannot explain the fluorescence enhancement attributed to Val-115.

\section{Asp-362 enhances the calcium sensitivity of GCaMP3}

Among the three substitution sites resulting in GCaMP3, N363D (Asp-362 in GCaMP3) is the only one involved in cal- cium binding and is responsible for the enhanced calcium sensitivity of GCaMP3 compared with GCaMP2 (Tian et al., 2009). For Asn-363 in GCaMP2, the side chain carbonyl group is involved in the coordination of $\mathrm{Ca}^{2+}$. Correspondingly, Asp-362 in GCaMP3 contributes its carboxyl group, which is chemically more active than a carbonyl group, for coordination. In fact, in our crystal structure of monomeric GCaMP ${ }_{\triangle R S E T} \cdot \mathrm{Ca}^{2+}$, the coordination bonds at the EF hand motif with Asp-362 decrease in length ( $0.08 \AA$ in average, $0.12 \AA$ maximally) compared with the corresponding calcium binding site in monomeric GCaMP2 $_{\triangle R S E T} \cdot \mathrm{Ca}^{2+}$ (PDB entry: 3EVR, Fig. 2D and 2E). The 
bond-length shortening indicates that the calcium binding site with Asp-362 can tether a Ca ${ }^{2+}$ more tightly than that with Asn-363.

CaM of GCaMPs has four calcium binding sites where calcium ions are coordinated in a pentagonal bipyramidal configuration as in EF hand motifs. At each site, one water molecule and one main chain carbonyl group, as well as the side chains of four residues including one Glu and at least two Asp, contribute their oxygen atoms to the coordination. The other residue involved is either Asp (two sites of four in GCaMP2) or Asn (the remaining two sites). Given the mutation from Asn to Asp, GCaMP3 possesses three sites with Asp and only one site with Asn. GCaMP3 exhibits higher affinity to $\mathrm{Ca}^{2+}$ and enhanced sensitivity to small calcium transients. Furthermore, the substitution of the only Asn with an Asp at the GCaMP3 calcium binding sites could be a rational consideration for the further improvement of $\mathrm{Ca}^{2+}$ sensitivity.

\section{Fluorophore status of GCaMP3 can be affected by pH conditions}

Fluorophore status can change under different $\mathrm{pH}$ conditions (Fig. 3B). This observation could result from the significant conformational changes of certain residues, such as His-148 and Thr-203 of GFP (Elsliger et al., 1999). To study the effect of $\mathrm{pH}$ condition to GCaMP3, we performed spectroscopic analysis at different $\mathrm{pH}$ conditions. According to its absorbance spectra, GCaMP3, with or without coordinated $\mathrm{Ca}^{2+}$, exhibits an increased absorption peak at $500 \mathrm{~nm}$ along with an increase in $\mathrm{pH}$ (Fig. 3B), which indicates that the fluorophore of GCaMP3 tends to be deprotonated in an alkaline environment.

Full-length GCaMP3 was also crystallized in different conditions with $\mathrm{Ca}^{2+}$, resulting in four dimeric GCaMP3. $\mathrm{Ca}^{2+}$ structures with only minor variance. The major difference was observedin Glu-60 of the M13 peptide, is the side chain of which branched out to the opposite directions. At $\mathrm{pH} 8.5$, the side chain of Glu-60 waved away from the cpEGFP $\beta$-barrel, whereas at $\mathrm{pH} 5.0$, it pointed closely to the $\beta$-barrel and replaced a water molecule (Fig. 2F). Both conformations were observed in two GCaMP3. $\mathrm{Ca}^{2+}$ crystals with different crystallization conditions at $\mathrm{pH}$ 7.5. In fact, the conformational difference of Glu60 also exists in the structures of dimeric GCaMP2, but was poorly discussed. Additionally, Glu-61 in a $\mathrm{Ca}^{2+}$ free-GCaMP2 structure has been reported to occupy the front of the $\beta$-barrel hole but is pulled away in a $\mathrm{Ca}^{2+}$-bound GCaMP2 structure (Akerboom et al., 2009). Therefore, the different orientations of the Glu-60 side chain at different $\mathrm{pH}$ conditions can possibly affect fluorophore status.

Tyr-380 in GCaMPJ prevents its dimerization and the solvent access to the $\beta$-barrel hole

In a previous work by Akerboomet et al., mutation D381Y of GCaMP2 was tested with a set of other mutants to determine their spectroscopic performance. Results showed that the fluorescence dynamic range of GCaMP2 ${ }_{\mathrm{D} 381 \mathrm{Y}}$ was the highest among all the tested mutants. The limited solvent accessibility to the hole in the cpEGFP $\beta$-barrel is the reason why mutation D381Y dramatically improves the fluorescence performance of GCaMP2. In our study, we introduced the mutation D380Y into GCaMP3 to create a better sensor called GCaMPJ. Spectroscopic studies showed that GCaMPJ is approximately $50 \%$ higher in $\Delta F / F_{0}$ than GCaMP3 $(30 \%$ higher for GCaMP2 ${ }_{\mathrm{D} 381 \mathrm{Y}}$ compared to GCaMP2 in previous studies), with a 1.3-fold increase of affinity for $\mathrm{Ca}^{2+}(173 \pm 12 \mathrm{nmol} / \mathrm{L}$ vs. $230 \pm 3 \mathrm{nmol} / \mathrm{L} ; P<0.01$ paired $t$-test, Fig. $4 \mathrm{~B}$ and $4 \mathrm{C})$.

To identify the exact function of Tyr-380 in GCaMPJ, we crystallized GCaMPJ and determined its structure. Unlike GCaMP2 or GCaMP3, GCaMPJ does not form dimers even under crystallization conditions (Fig. 4A). The crystal structure of GCaMPJ. $\mathrm{Ca}^{2+}$ consistently exhibits a monomeric form, generally identical to the structure of monomeric GCaMP $3_{\triangle R S E T} \cdot \mathrm{Ca}^{2+}$. The only significant difference, as expected, is that Tyr-380 approaches the $\beta$-barreland forms a hydrogen bond bridge with the main chain nitrogen of Ser-117 via a water molecule. The enhanced hydrogen bond network around the fluorophore facilitates the stabilization of its anionic phenol group. In addition, the relatively large side chain of Tyr380 blocks solvent accessibility to the hole in cpEGFP $\beta$-barrel, further protecting the deprotonated status of fluorophore phenolate, as proposed in previous studies (Fig. 4D).

In a further study, other three mutants at this site, namely, D380N, D380E, and D380F of GCaMP3, were introduced to confirm the function of D380Y in fluorescence properties and dimerization. Interestingly, the fluorescence dynamic range of $\mathrm{GCaMP}_{\mathrm{D} 380 \mathrm{~F}}$ is fairly close to that of GCaMPJ (Fig. 4E), indicating that the solvent accessibility limited by Tyr-380 or Phe380 could be the major reason for the increased fluorescence activities. However, the affinity for $\mathrm{Ca}^{2+}$ of $\mathrm{GCaMP} 3_{\mathrm{D} 380 \mathrm{~F}}$ was not improved compared with GCaMP3 (225 \pm 11 nmol/Lvs. $230 \pm$ $3 \mathrm{nmol} / \mathrm{L}, P>0.05$; paired $t$-test, Fig. $4 \mathrm{E}$ ), which is probably because Phe-380 cannot form a hydrogen bond like Tyr-380 with Ser-117. Thus, GCaMPJ can detect small calcium signals better. The dynamic range of GCaMP3 ${ }_{D 380 \mathrm{~N}}$ decrease to a level closed to GCaMP3 (Fig. 4E). Asn and Asp (in GCaMP3) share similar side chains. Surprisingly, the mutant GCaMP3 ${ }_{\mathrm{D} 380 \mathrm{E}}$ with a bigger side chain than the Asp-380 in GCaMP3 shows a significant decrease of dynamic range, which even lower than that of GCaMP3 (Fig. 4E).

Notably, Tyr-380 lies in loop a4-a5 because of its remarkable conformational difference between dimeric and monomeric forms of GCaMP3. To ascertain the role of Tyr380 in preventing dimerization, we analyzed the oligomer distribution of GCaMPJ and three other mutants through SEC analysis. Only GCaMP3 ${ }_{\mathrm{D} 380 \mathrm{~F}}$ has a dimer ratio of $15 \%$, close to that of GCaMPJ (10\%). Mutants GCaMP3 $3_{D 380 N}(35 \%)$ and GCaMP3 $_{\text {D380E }}(45 \%)$ are worse than GCaMP3 (28\%, Fig. 4F). Therefore, we believe that the spatial conflicts related to the large hydrophobic side chain of Tyr-380 could help to prevent the dimerization of GCaMPJ. 
A

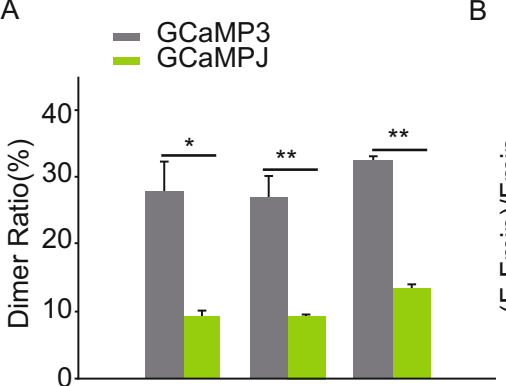

$\mathrm{pH} 8.5 \mathrm{pH} 7.5 \mathrm{pH} 6.5$

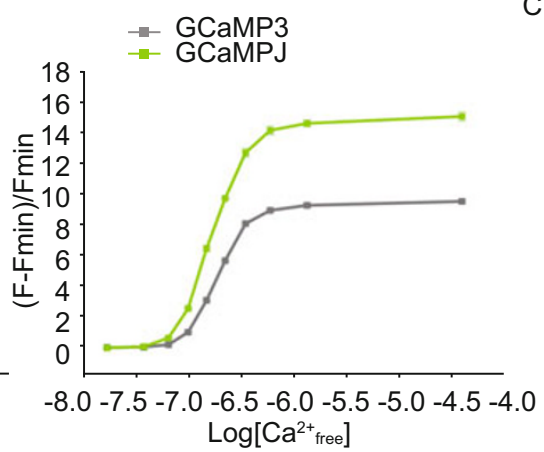

$\mathrm{E}$

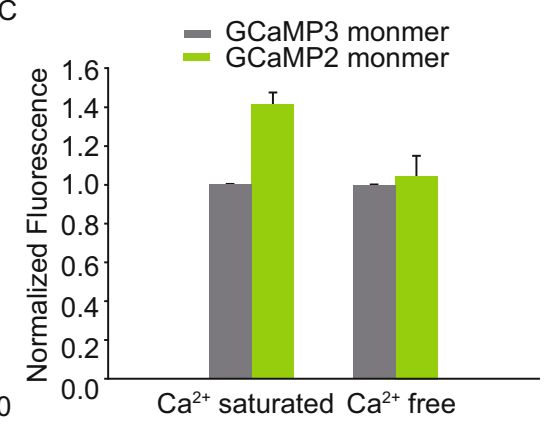

D

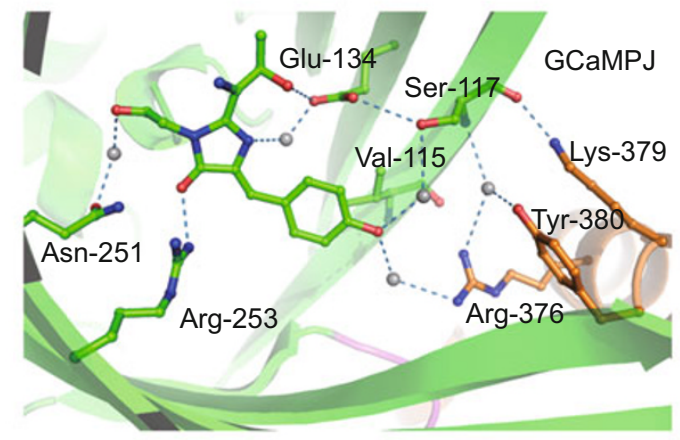

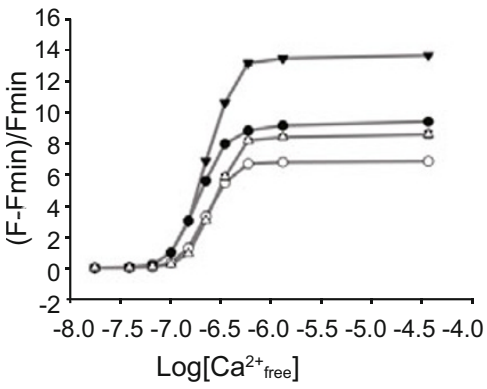

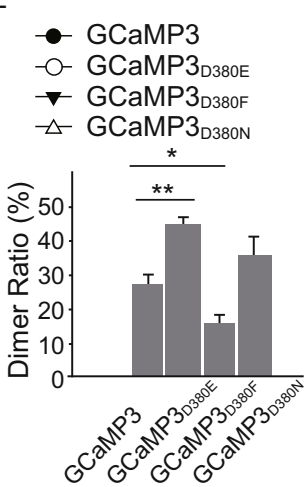

Figure 4. Function of Tyr-380 in GCaMPJ. (A) Dimer ratio of GCaMP3 (gray) and GCaMPJ (light green) analyzed by SEC atdifferent pH values. (B) $\mathrm{Ca}^{2+}$ titration assay shows the dynamic range of GCaMP3 (gray) and GCaMPJ (light green) in MOPS buffer. (C) Normalized fluorescence intensity of $\mathrm{Ca}^{2+}$ saturated state and $\mathrm{Ca}^{2+}$ free state of GCaMP3 monomer (gray) and GCaMPJ monomer (light green). Fluorescence intensity is normalized to the brightness of GCaMP3 in both states. (D) Close-up view of the fluorophore-interacting residues in $\mathrm{Ca}^{2+}$ bound monomeric GCaMPJ. Hydrogen bonds are shown as dashed lines. (E) Dimer ratio of GCaMP3D380E, GCaMP3D380F, and GCaMP3D380N at pH 7.5. (F) $\mathrm{Ca}^{2+}$ titration assay shows the dynamic range of GCaMP3D380E, GCaMP3D380F, and GCaMP3D380N in MOPS buffer.

\section{OUTLOOK}

For the future improvement of GCaMPs, further enhancement of the kinetic parameters of the sensors should be addressed. The fluorescence intensity, such as G-GECO that has a twofold intensity with unchanged calcium affinity, has been significantly increased compared with that of GCaMP3. However, for imaging calcium-related in vivo events with exceedingly rapid velocity or extremely minimal difference, a sensor with improved calcium affinity and binding kinetics must be employed. GCaMPJ has a comprehensively enhanced performance compared with GCaMP3 in terms of fluorescence intensity, calcium affinity, and dimerization prevention. Structural insight into GCaMP3 and GCaMPJ has shed light on the biochemical mechanism of the aforementioned enhancements and may promote further improvement.

\section{MATERIALS AND METHODS}

Protein expression and purification

Full-length GCaMP3 (Fig. 1A) and its mutants were subcloned into pET-28a vectors with an artificial small ubiquitin-related modifier
(SUMO)-tag inside Nhe1/BamH1 sites for further transformation of Escherichia coli strains. Transformed cells were grown overnight in lactose medium at $37^{\circ} \mathrm{C}$ and then harvested by centrifugation at $4000 \mathrm{~g}$ for $30 \mathrm{~min}$. The pellets were resuspended in lysis buffer $(137 \mathrm{mmol} / \mathrm{L}$ $\mathrm{NaCl}, 2.7 \mathrm{mmol} / \mathrm{L} \mathrm{KCl}, 50 \mathrm{mmol} / \mathrm{L} \mathrm{Na}_{2} \mathrm{HPO}_{4} \cdot 12 \mathrm{H}_{2} \mathrm{O}$, and $10 \mathrm{mmol} / \mathrm{L}$ $\left.\mathrm{KH}_{2} \mathrm{PO}_{4}, \mathrm{pH} 7.4\right)$ and then lysed by sonication. The lysates were then centrifuged at $18,000 \mathrm{~g}$ for $30 \mathrm{~min}$. The supernatant was loaded into a gravity-flow column containing $5 \mathrm{~mL}$ Ni-NTA affinity resin (Qiagen, USA). After washing the column with $50 \mathrm{~mL}$ of washing buffer (lysis buffer with $20 \mathrm{mmol} / \mathrm{L}$ imidazole), the target protein was eluted using an elution buffer (lysis buffer with $300 \mathrm{mmol} / \mathrm{L}$ imidazole). The protein was treated by Ulp1 enzyme overnight at $4^{\circ} \mathrm{C}$ after substituting the elution buffer with lysis buffer, after which it was reloaded to the Ni column to remove the SUMO tag. GCaMP3 and its mutants were eluted by a lysis buffer with $50 \mathrm{mmol} / \mathrm{L}$ imidazole. The eluted proteins were then applied onto a Superdex-200 gel filtration column (GE Healthcare, USA) equilibrated with buffer of different $\mathrm{pH}$ values. Fractions containing the target proteins were collected and concentrated for further studies.

Crystallization, data collection, and structure solution

GCaMP3 and its mutants were crystallized at $16^{\circ} \mathrm{C}$ through the hanging drop method. The crystals were grown in drops containing $1 \mu \mathrm{L}$ 
each of protein solution and reservoir. The crystals of GCaMP3 in $\mathrm{pH} 8.5$ were grown in $0.1 \mathrm{~mol} / \mathrm{L}$ 2-amino-2-hydroxymethyl-propane-1,3diol (Tris) at $\mathrm{pH} 8.5,0.2 \mathrm{~mol} / \mathrm{L}\left(\mathrm{NH}_{4}\right)_{2} \mathrm{SO}_{4}$, and $23 \%$ polyethylene glycol3350 (PEG3350). The two kinds of crystals of GCaMP3 at pH 7.5 were grown in $0.1 \mathrm{~mol} / \mathrm{L}$ 4-(2-hydroxyethyl)-1-piperazine ethane sulfonic acid (HEPES) at pH 7.5, $0.2 \mathrm{~mol} / \mathrm{L}\left(\mathrm{NH}_{4}\right)_{2} \mathrm{SO}_{4} 25 \%$ PEG3350, $0.1 \mathrm{~mol} / \mathrm{L} \mathrm{HEPES}$ at pH 7.5, $0.2 \mathrm{~mol} / \mathrm{L}\left(\mathrm{NH}_{4}\right)_{2} \mathrm{SO}_{4}$, and $21 \%$ PEG3350. The crystals of GCaMP3 at pH 5.0 were grown in $0.1 \mathrm{~mol} / \mathrm{LBis}-$ Trisat $\mathrm{pH} 5.0,0.2 \mathrm{~mol} / \mathrm{L}\left(\mathrm{NH}_{4}\right)_{2} \mathrm{SO}_{4}$, and 25\% PEG3350. The crystal condition of GCaMPJ at pH 7.5 was $0.1 \mathrm{~mol} / \mathrm{L}$ Tris at pH 7.5, $0.2 \mathrm{~mol} / \mathrm{L}\left(\mathrm{NH}_{4}\right)_{2} \mathrm{SO}_{4}$, and $25 \%$ PEG3350. The crystal condition of GCaMPJ at $\mathrm{pH} 8.5$ was $0.1 \mathrm{~mol} / \mathrm{L}$ Tris at $\mathrm{pH} 8.5,0.2 \mathrm{~mol} / \mathrm{L}\left(\mathrm{NH}_{4}\right)_{2} \mathrm{SO}_{4}, 25 \%$ PEG3350, and $0.5 \%$ dodecyl dimethylamine oxide. The crystals of GCaMP3 ${ }_{\triangle R E S T}$ were grown in $0.1 \mathrm{~mol} / \mathrm{L}$ Tris at $\mathrm{pH} 8.5,0.2 \mathrm{~mol} / \mathrm{L} \mathrm{NH}_{4} \mathrm{OAc}$, and $23 \%$ PEG3350. All crystals were flash-frozen by liquid nitrogen for data collection. The X-ray diffraction data on GCcMP3 at pH 8.5, GCaMP3 at $\mathrm{pH} 5.0$, and GCaMP $3_{\triangle R E S T}$ were collected using the in-house X-ray source, MicroMax 007 generator (Rigaku, Japan) combined with Varimax HR optics (Rigaku, Japan). The data on GCaMPJ at two pH values and GCaMP3 at pH 7.5 were collected using the beamline BL17U at the Shanghai Synchrotron Radiation Facility (Shanghai, China). The phasing problems were solved through molecular replacement with a program phaser (McCoy et al., 2007). The models were manually improved in COOT (Emsley and Cowtan, 2004). Refinements were conducted with RAFMAC (Murshudov et al., 1997) and PHENIX Refine (Adams et al., 2010). Refinement statistics are given in Table 1.

\section{Size exclusion chromatography (SEC)}

The $500 \mu \mathrm{L}$ protein sample applied onto a Superdex-200 column (GE Healthcare, USA) had a concentration of $50 \mu \mathrm{mol} / \mathrm{L}$. The absorbance at the 280,400 and $500 \mathrm{~nm}$ wavelengths was recorded as gel filtration was applied in different buffers $(20 \mathrm{mmol} / \mathrm{L}$ MES at pH 6.5, $150 \mathrm{mmol} / \mathrm{L}$ $\mathrm{NaCl}$, and $2 \mathrm{mmol} / \mathrm{L} \mathrm{CaCl} ; 20 \mathrm{mmol} / \mathrm{L}$ HEPES at $\mathrm{pH} 7.5,150 \mathrm{mmol} / \mathrm{L}$ $\mathrm{NaCl}$, and $2 \mathrm{mmol} / \mathrm{L} \mathrm{CaCl} ; 20 \mathrm{mmol} / \mathrm{L}$ Tris at $\mathrm{pH} 8.5,150 \mathrm{mmol} / \mathrm{L} \mathrm{NaCl}$, and $2 \mathrm{mmol} / \mathrm{L} \mathrm{CaCl}_{2}$ ). The peaks corresponding todimeric and monomeric fractions were integrated separately for thecalculation of the dimer ratio.

Table1. Data collection and refinement statistics

\begin{tabular}{|c|c|c|c|c|c|c|}
\hline & $\begin{array}{l}\text { GCaMPJ pH } 8.5 \\
\text { monomer }\end{array}$ & $\begin{array}{l}\text { GCaMP3 } \\
\mathrm{pH} 8.5 \text { dimer }\end{array}$ & $\begin{array}{l}\text { GCaMP3 } \\
\text { pH5.0 dimer }\end{array}$ & $\begin{array}{l}\triangle R \text { RSET-GCaMP3 } \\
\text { pH } 8.5 \text { monomer }\end{array}$ & $\begin{array}{l}\text { GCaMP3 } \\
\text { pH7.5 dimer } 1\end{array}$ & $\begin{array}{l}\text { GCaMP3 } \\
\text { pH } 7.5 \text { dimer } 2\end{array}$ \\
\hline \multicolumn{7}{|l|}{ Crystallographic data } \\
\hline$d_{\min }(\AA)$ & 2.0 & 2.0 & 2.0 & 2.4 & 1.48 & 1.4 \\
\hline Wavelength $(\AA)$ & 0.9794 & 1.5418 & 1.5418 & 1.5418 & 0.9794 & 0.9794 \\
\hline Measured reflections & 5316523 & 321693 & 223201 & 1087906 & 484325 & 903042 \\
\hline Average redundancy & $9.5(7.2)$ & $3.6(3.4)$ & $3.3(3.1)$ & $12.2(11.1)$ & $2.9(2.8)$ & $3.3(2.3)$ \\
\hline Mean $/ / \sigma(I)$ & $16.84(2.02)$ & $27.22(4.05)$ & $15.39(4.67)$ & $19.86(2.93)$ & $32.82(2.67)$ & $9.78(2.66)$ \\
\hline Completeness (\%) & $94.4(84.0)$ & $94.5(68.5)$ & $97.9(74.4)$ & $95.1(47.1)$ & 98.6(99.9) & $98.9(95.7)$ \\
\hline$R_{\text {merge }}{ }^{\mathrm{a}}$ & $10.2(84.4)$ & $4.2(33.4)$ & $3.5(23.3)$ & $12.0(81.4)$ & $4.4(39.8)$ & $9.6(31.1)$ \\
\hline \multicolumn{7}{|l|}{ Refinement statistics } \\
\hline Bragg spacing ( $(\AA)$ & $\begin{array}{l}37.93-2.00 \\
(2.04-2.00)\end{array}$ & $\begin{array}{l}31.01-2.00 \\
(2.08-2.00)\end{array}$ & $\begin{array}{l}22.11-2.01 \\
(2.09-2.01)\end{array}$ & $46.95-2.50$ & $\begin{array}{l}25.61-1.55 \\
(1.58-1.55)\end{array}$ & $\begin{array}{l}26.00-1.80 \\
(1.85-1.80)\end{array}$ \\
\hline Space group & P41212 & $\mathrm{C} 2$ & $\mathrm{C} 2$ & P41212 & $\mathrm{C} 2$ & $\mathrm{C} 2$ \\
\hline \multicolumn{7}{|l|}{ Cell parameters } \\
\hline$a(\AA)$ & 119.939 & 125.993 & 127.486 & 120.021 & 126.340 & 125.617 \\
\hline$b(\AA)$ & 119.939 & 46.614 & 46.917 & 120.021 & 47.352 & 46.749 \\
\hline$c(\AA)$ & 98.616 & 68.585 & 66.775 & 98.876 & 66.740 & 68.753 \\
\hline Reflection in working set & 46756 & 25346 & 35958 & 23529 & 55662 & 36019 \\
\hline Reflection in test set & 2374 & 1286 & 1318 & 1244 & 2842 & 1824 \\
\hline$R_{\text {work }}^{\mathrm{b}}$ & 17.33 & 18.49 & 17.19 & 17.58 & 17.90 & 16.14 \\
\hline$R_{\text {free }}{ }^{\mathrm{c}}$ & 20.47 & 21.43 & 21.21 & 22.79 & 20.89 & 19.83 \\
\hline r.m.s.d. bonds $(\AA)$ & 0.020 & 0.010 & 0.012 & 0.023 & 0.019 & 0.017 \\
\hline r.m.s.d. angles $\left({ }^{\circ}\right)$ & 1.718 & 0.966 & 1.105 & 1.998 & 1.514 & 1.550 \\
\hline Average B-factor $(\AA)$ & 41.86 & 33.87 & 36.53 & 42.67 & 28.28 & 22.12 \\
\hline Missing residures & 57 & 55 & 53 & 57 & 53 & 55 \\
\hline No. of waters & 359 & 240 & 262 & 378 & 543 & 450 \\
\hline
\end{tabular}

Valures in parentheses indicate the corresponding statistics in the highest resolution shell.

${ }^{a} R_{\text {merge }}=(\Sigma|i|</ i>\mid) / \Sigma|i|$, where $l i$ is the integrated intensity of a given reflection.

${ }^{\mathrm{b}} R_{\text {work }}=\left(\Sigma\left\|F_{0}|-| F_{\mathrm{C}}\right\|\right) / \Sigma\left|F_{0}\right|$, where $F_{0}$ and $F_{\mathrm{C}}$ denote observed and calculated structure factors, respectively.

${ }^{\mathrm{c}} R_{\text {free }}$ is equivalent to $R_{\text {work }}$ but caltulated using randomly chosen $5 \%$ reflections as the test set, which were excluded from refinement process. 


\section{Multi-angle light scattering (MALS)}

The weight-averaged molecular mass of GCaMP3 was determined using combined-size exclusion chromatography and multiple-angle laser light scattering. In summary, GCaMP3 $(0.05-0.5 \mathrm{mg})$ was injected onto an SEC column (WTC-030S5; Wyatt Technology) and eluted with buffer at $\mathrm{pH} 7.5(20 \mathrm{mmol} / \mathrm{L} \mathrm{HEPES}, 150 \mathrm{mmol} / \mathrm{L} \mathrm{NaCl}$, and $2 \mathrm{mmol} / \mathrm{L}$ $\mathrm{CaCl}_{2}$ ). The eluate was passed through a tandem UV detector (Gilson), laser light scattering detector (DAWN HELEOS II; Wyatt Technology), and differential Refractometer (Optilab T-rEX; Wyatt Technology) at a rate of $0.5 \mathrm{~mL} / \mathrm{min}$. The light scattering data were analyzed using Astra software (Wyatt Technology).

\section{Absorbance and fluorescence spectroscopy}

The absorbance spectra (350-550 nm; $2 \mathrm{~nm}$ path length) of purified proteins $(20 \mu \mathrm{mol} / \mathrm{L})$ were recorded at room temperatureand at different $\mathrm{pH}$ values $(100 \mathrm{mmol} / \mathrm{L}$ MES at $\mathrm{pH} 5.0$ and $6.3 ; 100 \mathrm{mmol} / \mathrm{L}$ HEPES at $\mathrm{pH} 7.4$; and $100 \mathrm{mmol} / \mathrm{L}$ Trisat $\mathrm{pH} 8.5$ ) in triplicate on a ThermoVarioskan spectrophotomer (Thermo, USA). Emission (500-550 nm) and excitation spectra $(350-508 \mathrm{~nm})$ were recorded at a protein concentration of $1.5 \mu \mathrm{mol} / \mathrm{L}$ in meta-object protocol (MOPS) buffer ( $30 \mathrm{mmol} / \mathrm{L}$ MOPS and $100 \mathrm{mmol} / \mathrm{L} \mathrm{KCl} ; \mathrm{pH} 7.40$ ) Fluorescence intensity was recorded at an excitation wavelength of $500 / 488 \mathrm{~nm}$ and emission wavelength of $512 / 515 \mathrm{~nm}$. The fluorescence intensity of $\mathrm{Ca}^{2+}$ at a saturated state $\left(1 \mathrm{mmol} / \mathrm{L} \mathrm{CaCl}_{2}\right)$ and $\mathrm{Ca}^{2+}$ at a free state $[10 \mathrm{mmol} / \mathrm{L}$ ethylene glycolbis (beta-aminoethyl ether)-N,N,N',N'-tetra acetic acid (EGTA)] were measured for each indicator (monomeric fraction) in MOPS buffer. The $\mathrm{Ca}^{2+}$ calibration buffer $\left(0 \mathrm{mmol} / \mathrm{L}\right.$ CaEGTA: $10 \mathrm{mmol} / \mathrm{L} \mathrm{K} \mathrm{K}_{2} \mathrm{EGTA}$, $100 \mathrm{mmol} / \mathrm{L} \mathrm{KCl}$, and $10 \mathrm{mmol} / \mathrm{L} \mathrm{MOPS} ; 10 \mathrm{mmol} / \mathrm{L} \mathrm{CaEGTA}: 10 \mathrm{mmol} / \mathrm{L}$ CaEGTA, $100 \mathrm{mmol} / \mathrm{L} \mathrm{KCl}$, and $10 \mathrm{mmol} / \mathrm{L} \mathrm{MOPS} ; \mathrm{pH}$ 7.40) was used to create $\mathrm{a} \mathrm{Ca}^{2+}$ titration assay to determine the $\mathrm{Ca}^{2+}$ sensitivity of purified proteins.

\section{ACKNOWLEDGEMENTS}

This work was supported by grants from the National Basic Research Program of China (Nos. 2011CB8091004 and 2009CB918701)

\section{REFERENCES}

Adams, P.D., Afonine, P.V., Bunkoczi, G., Chen, V.B., Davis, I.W., Echols, N., Headd, J.J., Hung, L.W., Kapral, G.J., Grosse-Kunstleve, R.W., et al. (2010). PHENIX: a comprehensive Python-based system for macromolecular structure solution. Acta Crystallogr D Biol Crystallogr 66, 213-221.

Akerboom, J., Rivera, J.D., Guilbe, M.M., Malave, E.C., Hernandez, H.H., Tian, L., Hires, S.A., Marvin, J.S., Looger, L.L., and Schreiter, E.R. (2009). Crystal structures of the GCaMP calcium sensor reveal the mechanism of fluorescence signal change and aid rational design. J Biol Chem 284, 6455-6464.

Borghuis, B.G., Tian, L., Xu, Y., Nikonov, S.S., Vardi, N., Zemelman, B.V., and Looger, L.L. (2011). Imaging light responses of targeted neuron populations in the rodent retina. J Neurosci 31, 2855-2867.

Brejc, K., Sixma, T.K., Kitts, P.A., Kain, S.R., Tsien, R.Y., Ormo, M., and Remington, S.J. (1997). Structural basis for dual excitation and photoisomerization of the Aequorea victoria green fluorescent protein. Proc Natl Acad Sci U S A 94, 2306-2311.

Chattoraj, M., King, B.A., Bublitz, G.U., and Boxer, S.G. (1996). Ultra- fast excited state dynamics in green fluorescent protein: multiple states and proton transfer. Proc Natl Acad Sci U S A 93,8362-8367.

Dombeck, D.A., Harvey, C.D., Tian, L., Looger, L.L., and Tank, D.W. (2010). Functional imaging of hippocampal place cells at cellular resolution during virtual navigation. Nat Neurosci 13, 1433-1440.

Elsliger, M.A., Wachter, R.M., Hanson, G.T., Kallio, K., and Remington, S.J. (1999). Structural and spectral response of green fluorescent protein variants to changes in $\mathrm{pH}$. Biochemistry 38, 5296-5301.

Emsley, P., and Cowtan, K. (2004). Coot: model-building tools for molecular graphics. Acta Crystallogr D Biol Crystallogr 60,2126-2132.

Hires, S.A., Tian, L., and Looger, L.L. (2008). Reporting neural activity with genetically encoded calcium indicators. Brain Cell Biol 36, $69-86$.

Ji, G., Feldman, M.E., Deng, K.Y., Greene, K.S., Wilson, J., Lee, J.C., Johnston, R.C., Rishniw, M., Tallini, Y., Zhang, J., et al. (2004). Ca2+-sensing transgenic mice: postsynaptic signaling in smooth muscle. J Biol Chem 279, 21461-21468.

Jung, G., Wiehler, J., and Zumbusch, A. (2005). The photophysics of green fluorescent protein: influence of the key amino acids at positions 65, 203, and 222. Biophys J 88,1932-1947.

Kotlikoff, M.I. (2007). Genetically encoded Ca2+ indicators: using genetics and molecular design to understand complex physiology. J Physiol 578, 55-67.

Kummer, A.D., Wiehler, J., Rehaber, H., Kompa, C., Steipe, B., and Michel-Beyerle, M.E. (2000). Effects of threonine 203 replacements on excited-state dynamics and fluorescence properties of the green fluorescent protein (GFP). J Physical Chem B 104, 4791-4798.

McCoy, A.J., Grosse-Kunstleve, R.W., Adams, P.D., Winn, M.D., Storoni, L.C., and Read, R.J. (2007). Phaser crystallographic software. J Appl Crystallogr 40, 658-674.

Murshudov, G.N., Vagin, A.A., and Dodson, E.J. (1997). Refinement of macromolecular structures by the maximum-likelihood method. Acta Crystallogr D Biol Crystallogr 53, 240-255.

Nagai, T., Sawano, A., Park, E.S., and Miyawaki, A. (2001). Circularly permuted green fluorescent proteins engineered to sense Ca2+. Proc Natl Acad Sci U S A 98, 3197-3202.

Ohkura, M., Matsuzaki, M., Kasai, H., Imoto, K., and Nakai, J. (2005). Genetically encoded bright $\mathrm{Ca} 2+$ probe applicable for dynamic $\mathrm{Ca} 2+$ imaging of dendritic spines. Anal Chem 77, 5861-5869.

Ormo, M., Cubitt, A.B., Kallio, K., Gross, L.A., Tsien, R.Y., and Remington, S.J. (1996). Crystal structure of the Aequorea victoria green fluorescent protein. Science 273, 1392-1395.

Seelig, J.D., Chiappe, M.E., Lott, G.K., Dutta, A., Osborne, J.E., Reiser, M.B., and Jayaraman, V. (2010). Two-photon calcium imaging from head-fixed Drosophila during optomotor walking behavior. Nat Methods 7, 535-540.

Shiba, Y., Fernandes, S., Zhu, W.Z., Filice, D., Muskheli, V., Kim, J., Palpant, N.J., Gantz, J., Moyes, K.W., Reinecke, H., et al. (2012). Human ES-cell-derived cardiomyocytes electrically couple and suppress arrhythmias in injured hearts. Nature 489, 322-325

Stoner-Ma, D., Jaye, A.A., Matousek, P., Towrie, M., Meech, S.R., and Tonge, P.J. (2005). Observation of excited-state proton transfer in green fluorescent protein using ultrafast vibrational spectroscopy. J Am Chem Soc 127, 2864-2865.

Tallini, Y.N., Ohkura, M., Choi, B.R., Ji, G., Imoto, K., Doran, R., Lee, J., Plan, P., Wilson, J., Xin, H.B., et al. (2006). Imaging cellular signals in the heart in vivo: Cardiac expression of the high-signal $\mathrm{Ca} 2+$ in- 
dicator GCaMP2. Proc Natl Acad Sci U S A 103, 4753-4758.

Tian, L., Hires, S.A., Mao, T., Huber, D., Chiappe, M.E., Chalasani, S.H., Petreanu, L., Akerboom, J., McKinney, S.A., Schreiter, E.R., et al. (2009). Imaging neural activity in worms, flies and mice with improved GCaMP calcium indicators. Nat Methods 6, 875-881.

Tsien, R.Y. (1998). The green fluorescent protein. Annu Rev Biochem $67,509-544$.

Wang, Q., Shui, B., Kotlikoff, M.I., and Sondermann, H. (2008). Struc- tural basis for calcium sensing by GCaMP2. Structure 16,18171827.

Yang, F., Moss, L.G., and Phillips, G.N., Jr. (1996). The molecular structure of green fluorescent protein. Nat Biotechnol 14,1246-1251.

Zhao, Y., Araki, S., Wu, J., Teramoto, T., Chang, Y.F., Nakano, M., Abdelfattah, A.S., Fujiwara, M., Ishihara, T., Nagai, T., et al. (2011). An expanded palette of genetically encoded $\mathrm{Ca}(2)(+)$ indicators. Science 333,1888-1891. 